\title{
Finding Balance: A Challenge for Untenured Faculty
}

\author{
Katherine O'Connor \\ East Carolina University
}

121 Mamie Jenkins Road, Greenville, North Carolina, 27858, USA

Tel: 1-252-328-5466_E-mail: oconnork@ecu.edu

\section{H. Carol Greene}

East Carolina University

207 Speight Building, Mailstop 504, Greenville, North Carolina, 27858, USA

Tel: 1-252-328-5316 E-mail: greeneh@ecu.edu

Amy J. Good (Corresponding Author)

The University of North Carolina at Charlotte

UNC Charlotte, Reading \& Elementary Education, COED 375, Charlotte, North Carolina, 28223, USA

Tel: 1-704-687-8624 E-mail: a.good@uncc.edu

\author{
Guili Zhang
}

East Carolina University

232 Speight Building, Mailstop 504, Greenville, North Carolina, 27858, USA

Tel: 1-252-328-6833 E-mail: zhangg@ecu.edu

\author{
Received: May 30, 2011 Accepted: June 16, 2011 Published: November 1, 2011 \\ doi:10.5539/ies.v4n4p3 URL: http://dx.doi.org/10.5539/ies.v4n4p3
}

\begin{abstract}
This study investigated the impact of work overload on untenured faculty $(n=38)$ who teach, research, and serve in the colleges of education at two research intensive universities in the United States. Both of these colleges of education are moving toward a research focus. The transition has created an overload situation by establishing high research expectations while continuing to expect a high teaching load. Thus, the researchers investigated the following two guiding questions: (1) When a college establishes a stronger research focus, does it have a negative impact on untenured faculty? and (2) In what ways can a college (or institution) build support strategies for untenured faculty working an overload? The following ways were mentioned in regards to supporting untenured faculty: (a) make supporting untenured faculty members an institutional priority, (b) have a "point person" who would inform untenured faculty members about deadlines, tenure procedures, etc., (c) assign a research, publication, grant and/or tenure mentor, (d) find ways to reduce high teaching loads if there are also high research expectations, and (e) receive constructive feedback about research.
\end{abstract}

Keywords: Untenured faculty, Untenured faculty expectations, Faculty support systems

\section{Introduction}

A phenomenon known in the literature as "upward drift" (Aldersley, 1995, p. 1) refers to the trend for institutions to move to a higher Carnegie classification, including changing their names from college to university and a desire to gain more prestige at a research level. The authors propose an upward drift movement may, in fact, impact untenured faculty and the workloads they carry. Using a case study approach, the researchers investigated the following guiding questions related to two colleges of education: (a) When a college establishes a stronger research focus, does it have a negative impact on untenured faculty? and (b) In what ways can a college (or institution) build support strategies for untenured faculty working an overload? 


\section{Background Information}

The initial phase of the study was conducted by six professors at a large public research university in the United States to gain understanding of untenured faculty experiences. Participants in the research included 96 untenured assistant professors in the field of education from eight public universities across one state in the Southeast. Among the 191 untenured professors who were invited to participate, 96 participated yielding a 50\% response rate. Using the current Carnegie classifications, $11 \%$ of the respondents were from Research Extensive or Research I institutions, $60 \%$ were from Research Intensive or Research II institutions, and 29\% were from Comprehensive institutions. Response rates were $27 \%, 55 \%$, and $57 \%$ respectively from each Research Intensive institution coded as University A, University B and University C (Greene, O’Connor, Good, Ledford, Peel \& Zhang, 2008).

Findings from the initial study indicated that a disparity in workload was occurring at two of the three Research Intensive universities, University B and University C. According to the Carnegie classification, a research extensive university would have a load of $40 \%$ teaching, $40 \%$ research and $20 \%$ service which equals a $100 \%$ workload. Typically, two publications per year are expected as a result of the $40 \%$ research load and six credits per semester, or twelve credits per year, are expected for the $40 \%$ teaching load. Faculty members at University A were working at a $100 \%$ workload. However, Universities B and C worked at $120 \%$ and $130 \%$ load capacity respectively (Greene et al., 2008).

This overload was determined by applying the Carnegie classification and standard expectations within that system. For example, a $40 \%$ research load assumes two publications per year. Thus, it takes $20 \%$ of time per publication. Because expectations are two and a half publications per year at University B, this would require a $50 \%$ research load; however, they only receive $30 \%$ of their time for research because they spend $50 \%$ of their time on teaching 15-18 credits per year. Expectations at University C are two publications per year, which would require a $40 \%$ research load; however, they only receive $10 \%$ of their time for research because they spend $70 \%$ of their time on teaching 21 credits per year (nine credits one semester and 12 credits the other semester). University C is expected to publish the same amount as the research extensive universities in the original sample (two articles per year) with $30 \%$ less time per year to do so, while University B is expected to actually publish more than the research extensive universities in the sample with $10 \%$ less time to do so (Greene et al., 2008). This creates the overload defined for this paper: more work is expected than time available within the workload to do it without additional compensation. This manuscript focuses on the two colleges of education with documented overloads.

\section{Theoretical Framework}

The apprehension and challenges that new faculty face is acknowledged in the research (e.g., Hamilton, 2005; Mullen \& Forbes, 2000; Olsen, 1993; Olsen \& Crawford, 1998; Rice, Sorcinelli, \& Austin, 2000; Sorcinelli, 1994; Whitt, 1991). Reports from research completed with these novice higher education faculty members included statements about leading unbalanced lives and working in isolated environments. The authors of this study propose that another reason for faculty apprehension may occur when colleges of education begin to transition to a more research extensive focus. As a result, for the participants in this study, there is an expectation of increased research production without changing teaching or service expectations.

Morphew (2002) indicated that since 1990, more than 120 public and private four-year colleges have changed their names and became universities. These changes in name are also known as "academic drift." So why do colleges transform themselves into universities? Morphew proposed three possibilities: "Colleges become universities to seem more legitimate to the external environment; colleges become universities to secure important tangible resources; colleges become universities to better reflect their increased comprehensive nature" (2002, p. 209).

Although the universities in this study are not changing their names, two colleges of education in particular are moving toward a more research focus. This type of drift can be referred to as "upward drift" (Aldersley, 1995; Spangler, 1991). Aldersley (1995) defined the phenomenon "upward drift" (p.1) as the tendency for institutions "to introduce higher-level programs" and create an increase in research. Spangler (1991) found in her report that the majority of universities and colleges she studied caught in an upward drift began as teacher preparation colleges. She offered four suggestions regarding finances, accountability, mission, and teaching to universities and colleges making the upward move (1991). This research study is based on the notion that colleges of education going through "upward drift" may unintentionally affect untenured faculty. Particularly, as departments or colleges move in a more research-centered direction to obtain increased resources and gain more legitimacy, all faculty members will experience change, but the effect, specifically on untenured faculty members, cannot be ignored.

Morphew, Toma, and Hedstrom (2001) mention that "change-even monumental change-is possible for higher education when the necessary ingredients are in place and used properly by an institution and its leaders" (p. 30). Universities need to consider structural changes, including implementing a unique support model exclusive to a 
university's mission and culture. A suggested support model by Greene et al. (2008) includes six components: research support, mentor support, limited responsibilities, clear expectations, open communication, and a collegial and welcoming environment. Greene et al. (2008) recommend that for balance to occur and for support systems to be effective, there must be a match between the expectations placed on both new and tenured faculty and the assigned workload available to complete those expectations. Finding faculty balance is not a new recommendation in the literature (Boice, 1992; Moody, 1997; Rice et al, 2000; Sorcinelli, 2000).

\section{Methods}

The current investigation is an extension of the initial study and was accomplished by using a case study approach. A case study design was chosen because it allowed the researchers to focus on a particular phenomenon and to probe and gain a deeper understanding of the phenomenon (Gall, Borg, \& Gall, 1996). The focus for this particular case study is an examination of one case involving two universities and the impact of the $120 \%$ and $130 \%$ workload on untenured faculty who work at these universities, along with an investigation as to why such an overload is occurring.

The survey was designed as a cross sectional survey to gather information related to the experiences and perceptions of a specific sample population. The purpose of this type of survey was to generalize from the sample to the broader population so that inferences could be made about the perceptions and experiences of the population as a whole. With the intention of ensuring survey validity, five experts were asked to review the survey and a field test was carried out in which eight faculty members responded to the survey and the survey was revised based upon pilot findings reported to the research team. Additionally, the survey demonstrated very good reliability through test and retest $(\mathrm{r}=.89)$.

Once the survey was piloted and revised, data were collected via an online, secure, website-based survey (Appendix A) for a 12-week period during the spring semester of 2006. Thirty-eight untenured faculty members in the colleges of education from the two universities with overloads, which we will refer to as Universities B and C, completed the online survey. The survey contained requests for background and demographic information, and included opportunities for both quantitative-style responses as well as narrative responses. Respondents answered questions related to typically assigned loads, tenure expectations, and types of support available to them. They were also asked to describe supports that were not available to them, but that they believe would have been helpful for them in their progress toward tenure. While the survey is very effective in directly answering the guiding questions in this study, in order for it to achieve wide usefulness, a factor analysis may be further conducted to statistically summarize the factors underlying these particular survey items.

Data analysis involved qualitative methodologies. A systematic qualitative data analysis approach was used which involved reading and rereading the text and color highlighting the sentences and phrases that related to themes suggested by the research questions. To search systematically for emerging themes and patterns, the data were examined multiple times. Any recurring themes that emerged were documented in a template (Miles \& Huberman, 1994). This process was followed to answer two guiding questions: (1) When a college establishes a stronger research focus, does it have a negative impact on untenured faculty? and (2) In what ways can a college (or institution) build support strategies for untenured faculty working an overload?

\section{Findings}

Findings related to faculty needs and suggested supports are presented in this section.

\subsection{Faculty Needs}

When asked about teaching and research expectations, the majority $(\mathrm{n}=29)$ of the participants said both publishing and teaching were top priorities. Four respondents left this item blank. This clearly identifies the pull felt between the two. Additionally, only four of the participants in the study mentioned finding a balance in their workload and meeting the expectations for tenure. Those who did find balance did so by writing with a group of colleagues or having time reassigned due to a grant. However, the majority of participants did not find balance. Many mentioned working on weekends, writing only during breaks and holidays, working 80 hours a week, sacrificing a personal life, and eliminating proper health choices and exercise.

Many obstacles were mentioned as to why balance could not be achieved including: (a) not being able to protect scheduled writing time, (b) continually teaching new classes, (c) teaching high loads, (d) having large class enrollments, (e) assisting too many advisees, and (f) having program coordinator and other administrative responsibilities. Multiple course preparations particularly appear to be a drawback for untenured faculty. Twenty-one faculty members reported having one to two different course preps per semester, while 16 faculty members reported having three to four different course preps per semester. 
When asked what ways they have been supported toward tenure, the majority of respondents mentioned many types of research support including: research release time, clear research expectations, helpful annual and personnel committee evaluations, supportive colleagues, departmental orientation and informational meetings, university seminars, assistance with research and publications, graduate assistantship, encouragement and feedback from the department and college administration, and travel funds. The only mention of support in a teaching capacity was the sharing of course syllabi and the use of, and availability of, unlimited technology.

Mentoring was also mentioned frequently. Two-thirds of the participants reported having formal or informal mentors. This news sounds promising until comments are coded more thoroughly. There was a wide range of support provided by the mentors. While some respondents had positive and reciprocal experiences with their mentors, others found the relationship to be less than helpful. One respondent summed it up, "Assigning mentors is a great concept; however, like in the public schools, the competence and aptitude of mentors varies." When asked what types of support they had not received that they believe would have been helpful for them, mentoring and realistic teaching load were most frequently mentioned.

\subsection{Supporting Untenured Faculty}

Consequently, what can colleges of education and institutions do to build supports and strategies for untenured faculty working with an overload? Respondents from these two institutions shared many ideas.

5.2.1 Priority. One idea that was often mentioned by the respondents was that supporting untenured faculty must be considered an institutional priority. This idea of priority means an institution has a clear vision for all faculty members. One respondent stated that she wanted, "An institution that knows what it wants to be and is fully committed to that end. You can't force a person to teach 100-150 students and 4 classes per term and expect them to be profuse publishers."

Department chairs can make supporting untenured faculty a priority. Department chairs can deliberately protect new professors from overloads, including making it acceptable to decline too many service or course related opportunities. Another way to make supporting untenured faculty a priority is to offer funds for research projects. Many times, untenured faculty members need start-up funds to begin a line of effective research or to use as a course buy-out. This type of solution would be two-fold. It supports the institution moving in a research direction and supports untenured faculty members simultaneously. Finally, a paid sabbatical prior to tenure was another suggestion about how an institution could make untenured faculty support a priority.

5.2.2 One source of information. Another strategy mentioned by respondents was to have one source of information for untenured faculty. Untenured faculty wanted a "point person" who would inform them about deadlines, tenure procedures, etc. For example one person said, "I think the chair of the personnel committee should meet with the new faculty members and discuss deadlines and reappointment criterion. All forms should be provided to new faculty members up front instead of the day before they are due." This type of communication is helpful to untenured faculty members because the message is clear and many times people who are overloaded need comprehensible and unambiguous guidelines for teaching, research, service and tenure. A respondent speaks to this notion of having an untenured faculty point person:

Many people (and) departments try to help and this is nice to a point; however, you end up with a broad, noisy message of contradictions instead of one narrow, clear source of information. The message would be delivered much more effectively if I did not have to filter out the noise in the message.

5.2.3 Publication and tenure mentor. Respondents repeatedly mentioned wanting a mentor to assist with developing a line of research, publishing manuscripts, obtaining grants and achieving tenure. This sounds like a feasible goal; however, many possible mentors are already very busy tenured faculty members who cannot take on one extra responsibility. Tenured faculty need to be compensated to mentor untenured faculty members. Paying a person to mentor a new faculty member would save money in the long run. If an untenured faculty member vacates his/her position, then the institution has to begin the expense of another job search. Instead, a tenured faculty member can offer quality support and he/she is accountable for the mentoring work because payment, reassignment time of another form of compensation is involved. One respondent mentioned that "linking new professors with seasoned tenured professors with the knowledge and expertise to increase research and publication skills" should be a strategy used. Quality mentoring made a difference to this respondent, "I honestly think the two things that my mentor did for me that helped me the most were helping me to get published and asking me out to dinner Friday nights." Having dedicated mentors during an institution's research extensive transition time is important.

5.2.4 Teaching reduction. Although the reduction of teaching as a form of support seems obvious, it must be noted. Many respondents stated that the range of nine to 15 credits and higher workload is too heavy when an institution 
wants to move toward being research extensive. Institutions that leap into the research extensive category, without strategically planning how to get there successfully, can fail. Additional options related to teaching that must be considered include reducing course preparations, limiting the number of new course preparations, and paying untenured faculty to arrive two to three weeks prior to the fall semester to prepare course materials and to obtain any training in online teaching.

5.2.5 Feedback. Untenured faculty stated that feedback about their research was a much desired support. Specifically, some respondents wanted, "access to a research center designed to support faculty research efforts (everything from identifying publishing outlets to providing collegial critiques of manuscripts)" and "collaborative work groups geared toward developing a line of research." Another strategy cited was to plan monthly meetings with a coordinator for new faculty "to bring our 'stuff' and share or get feedback." Blocking out time to write and work on publications needs to occur. Faculty members block out time for teaching; thus, if an institution makes a commitment to move in a research direction, then having uninterrupted time to plan a research study, collect data, analyze data and publish data must be non-negotiable.

\section{Conclusion}

The overload for these two colleges of education is documented (Greene et al., 2008), but why is the overload occurring? The authors propose that the overload is occurring because at times universities or specifically colleges of education particular to this study may be trying to be omniscient (trying to be everything to everyone). Universities and colleges in these situations need to pause and examine their infrastructure, workloads, and support systems currently in place. Institutions must listen to all their faculty members before they change too quickly. The imbalance and high workload that faculty are reporting could negatively influence the quality of the work and programs needed for the next step of stature. According to the respondents, many supports were available from their universities, but not all the supports in the world can accommodate a workload that demands more productivity than time in the work week in which to accomplish it.

When asked to describe an ideal support system, one untenured faculty member stated, "I am not sure, this is the only thing I have known and all I know is that it isn't working." Change is essential for institutions, but the rate of the change needs to be monitored. Universities must consider the proper infrastructure and administrative costs (Morphew \& Baker, 2004) and deliberate the university's intended mission (A SCHEV report, 2003; Spangler, 1991). According to these findings, a faculty support center, research mentors, a reduced teaching load, and research assistance are components of a needed infrastructure for these college of education untenured faculty members. Universities need to equip faculty members with support strategies for successful and thoughtful upward movement as opposed to being caught in an unbalanced drift.

\section{Future Research Directions}

This study and the previous study (Greene et al., 2008) focused on untenured faculty in colleges of education. Future research should be conducted in other departments, schools and colleges beyond colleges of education. Typically, instructors in colleges of education have backgrounds in teaching and may request assistance in their research area, not their teaching area, because teaching is their discipline. Furthermore, implementing and studying the effects of a comprehensive support system model would be beneficial to the literature base. Finally, conducting a longitudinal study in which assistant professors are followed through their tenure experience could reap the best information possible because we could learn firsthand if support strategies are in place and how those strategies change with a person's tenure experience. Researchers could investigate if associate and full professors need support strategies and if they are obtaining what they need to be successful as well.

\section{References}

A SCHEV Report. (2003). Report to the Governor and General Assembly. A study of factors that have contributed to mission change in public colleges and universities. State Council of Higher Education for Virginia Advancing Virginia through Higher Education.

Aldersley, S. F. (1995). "Upward drift" is alive and well: Research/doctoral model still attractive to institutions. Change, 27(5), 50-55. http://dx.doi.org/10.1080/00091383.1995.9936448

Boice, R. (1992). The new faculty member: Supporting and fostering professional development. San Francisco: Jossey-Bass.

Gall, M. D., Borg, W. R., \& Gall, J. P. (1996). Educational research: An introduction. White Plains, NY: Longman. 
Greene, H. C., O'Connor, K. A., Good, A. J., Ledford, C. C., Peel, B. B., \& Zhang, G. (2008). Building a support system toward tenure: Challenges and needs of tenure-track faculty in colleges of education. Mentor \& Tutoring: Partnership in Learning, 16(4), 429-447. http://dx.doi.org/10.1080/13611260802433791

Hamilton, K. (2005). Getting off the burnout track. Diverse: Issues in Higher Education, 22, 26-31

Miles, M. B., \& Huberman, A. M. (1994). Qualitative data analysis: An expanded sourcebook, (2nd ed). Thousand Oaks, CA: Sage.

Moody, J. (1997). Demystifying the profession: Helping junior faculty succeed. West Haven, CT: University of New Haven Press.

Morphew, C. C. (2002). "A rose by any other name": Which colleges became universities. The Review of Higher Education, 25(2), 207-223. http://dx.doi.org/10.1353/rhe.2002.0005

Morphew, C. C., \& Baker, B. D. (2004). The cost of prestige: Do new research I universities incur higher administrative costs? The Review of Higher Education, 27(3), 365-384. http://dx.doi.org/10.1353/rhe.2004.0005

Morphew, C. C., Toma, J. D., \& Hedstrom, C. Z. (2001). The public liberal arts college: Case studies of institutions that have bucked the trend toward "upward drift"... and the implications for mission and market. Association for the Study of Higher Education.

Mullen, C. A., \& Forbes, S. (2000). Untenured faculty: Issues of transition, adjustment and mentorship. Mentoring and Tutoring, 8(1), 31-46. http://dx.doi.org/10.1080/713685508

Olsen, D. (1993). Work satisfaction and stress. Journal of Higher Education, 64, 453-471. http://dx.doi.org/10.2307/2960052

Olsen, D., \& Crawford, L. A. (1998). A five-year study of junior faculty expectations about their work. The Review of Higher Education, 22(1), 39-54

Rice, R., Sorcinelli, M., \& Austin, A. (2000). Heeding new voices: Academic careers for a new generation. Washington, DC: American Association for Higher Education.

Sorcinelli, M. D. (1994). Effective approaches to new faculty development. Journal of Counseling \& Development, $72,474-479$

Sorcinelli, M. D. (2000). Principles of good practice: Supporting early career faculty, guidance for deans, department chairs and other academic leaders. Washington, DC: American Association for Higher Education.

Spangler, M. S. (1991). Caught in "upward drift": An assessment of comprehensive universities and colleges. (ERIC Document Reproduction Service No. ED333777)

Whitt, E. (1991, Winter). Hit the ground running: Experiences of new faculty in a school of education. Review of Higher Education, 14(2), 177-197

\section{APPENDIX A}

\section{Pretenured Survey}

Directions: Please fill out the following questions regarding your expectations for tenure and the types of support you receive as you pursue tenure. All answers are confidential.

\section{Part A: Demographic Information}

1. According to the Carnegie classifications listed below, choose the best description of your current institution.

Doctoral Research University Extensive (Research One)

Doctoral Research University Intensive (Research Two)

Masters College and University One

Masters College and University Two

Baccalaureate College

2. How many years have you worked in your current position? years 
3. How many total years have you worked in higher education? (Include working in a tenure track position at other institutions.)

years

4. Choose the one answer which best describes your current position.

Adjunct Professor

Assistant Professor without tenure

Assistant Professor with tenure

Associate Professor without tenure

Associate Professor with tenure

Full Professor

Other:

5. To what department and program area are you assigned?

Department:

Program Area:

6. Please describe your typical fall assigned teaching load.

0-3 semester hours

4-6 semester hours

7-9 semester hours

10-12 semester hours

13-15 semester hours

Over 15 semester hours

7. Please describe your typical fall assigned research load.

0-3 semester hours

4-6 semester hours

7-9 semester hours

10-12 semester hours

13-15 semester hours

Over 15 semester hours

8. Please describe your typical spring assigned teaching load.

0-3 semester hours

4-6 semester hours

7-9 semester hours

10-12 semester hours

13-15 semester hours

Over 15 semester hours

9. Please describe your typical spring assigned research load.

0-3 semester hours

4-6 semester hours

7-9 semester hours

10-12 semester hours

13-15 semester hours

Over 15 semester hours 
10. Please describe the number of credit hours you receive for other activities such as administrative reassignments, etc. not related to teaching or research.

$0-3$ semester hours

4-6 semester hours

7-9 semester hours

10-12 semester hours

13-15 semester hours

Over 15 semester hours

11. In the box below, please provide the percentage of time you are assigned to spend on teaching, research, service, or other activities such as administrative reassignments, etc.

Example:

\begin{tabular}{|c|c|}
\hline Teaching & Research \\
\hline Service & Other \\
\hline
\end{tabular}

\begin{tabular}{|c|c|}
\hline $\begin{array}{c}\text { Teaching } \\
40 \%\end{array}$ & $\begin{array}{c}\text { Research } \\
50 \%\end{array}$ \\
\hline Service & Other \\
$10 \%$ & $0 \%$ \\
\hline
\end{tabular}

12. On average, how many advisees do you work with each year?

$0-5$

6-10

$11-15$

$16-20$

$21-25$

26-30

31 or more

13. How many hours of graduate courses do you teach on average per semester?

0

$1-3$

4-6

7-9

10-12

More than 12

14. How many different preps do you typically have during each semester? (i.e., Three different courses would be three preps, three sections of the same course would be one prep)

Never more than 1

$1-2$

$3-4$

More than 4

15. Of your typical teaching load, how many credit hours involve online instruction?

0

$1-3$

$4-6$

7-9 
$10-12$

More than 12

16. How many actual hours per week do you spend supervising course related field experiences?

0

$1-3$

$4-6$

7-9

$10-12$

More than 12

17. How many credit hours are you assigned to supervise such field experiences?

0

1

2

3

4

5 or more

18. How many days per week do you typically teach classes?

0

1

2

3

4

5

19. What is the average class size that you teach in the undergraduate program?

10 students or less

11-20 students

21-30 students

31-40 students

41-50 students

51-100

Over 100

I don't teach undergraduate students.

20. What is the average class size that you teach in the graduate program?

10 students or less

11-20 students

21-30 students

31-40 students

41-50 students

Over 50 students

I don't teach graduate students. 


\section{Part B: Tenure Expectations}

1. What expectations were given to you when you arrived regarding teaching and research?

2. What expectations were given to you when you arrived regarding successful progress toward tenure?

3. How do you balance meeting these expectations?

4. What has been difficult for you as you strive to balance these expectations?

5. What has been helpful for you as you strive to balance these expectations?

\section{Part C: Support Section}

1. Do you have an informal or formally assigned mentor? Yes No

Please describe.

2. How do you perceive the support you have received in the following areas?

$(5=$ superior support, $4=$ good support, $3=$ average support, $2=$ below average support, $1=10 \mathrm{w} / \mathrm{minimal}$ support)

Research

Teaching

Service

Technology needs

GA needs

$\begin{array}{lllll}5 & 4 & 3 & 2 & 1 \\ 5 & 4 & 3 & 2 & 1 \\ 5 & 4 & 3 & 2 & 1 \\ 5 & 4 & 3 & 2 & 1 \\ 5 & 4 & 3 & 2 & 1\end{array}$

3. In what ways have you been supported in your progress toward tenure?

4. What help do you wish you would have received, but did not?

5. Please describe what you would consider to be an ideal support system for new professors. 